\title{
Fungal ABC Transporters and Microbial Interactions in Natural Environments
}

\author{
Henk-jan Schoonbeek, Jos M. Raaijmakers, and Maarten A. De Waard \\ Laboratory of Phytopathology, Department of Plant Sciences, Wageningen University, P.O. Box 8025, 6700 EE, \\ Wageningen, The Netherlands
}

Submitted 17 June 2002. Accepted 12 July 2002.

In natural environments, microorganisms are exposed to a wide variety of antibiotic compounds produced by competing organisms. Target organisms have evolved various mechanisms of natural resistance to these metabolites. In this study, the role of ATP-binding cassette (ABC) transporters in interactions between the plant-pathogenic fungus Botrytis cinerea and antibiotic-producing Pseudomonas bacteria was investigated in detail. We discovered that 2,4diacetylphloroglucinol, phenazine-1-carboxylic acid and phenazine-1-carboxamide (PCN), broad-spectrum antibiotics produced by Pseudomonas spp., induced expression of several ABC transporter genes in $B$. cinerea. Phenazines strongly induced expression of $B c a t r B$, and $\triangle B c a t r B$ mutants were significantly more sensitive to these antibiotics than their parental strain. Treatment of $B$. cinerea germlings with PCN strongly affected the accumulation of $\left[{ }^{14} \mathrm{C}\right]$ fludioxonil, a phenylpyrrole fungicide known to be transported by BcatrB, indicating that phenazines also are transported by BcatrB. Pseudomonas strains producing phenazines displayed a stronger antagonistic activity in vitro toward $\Delta$ BcatrB mutants than to the parental $B$. cinerea strain. On tomato leaves, phenazine-producing Pseudomonas strains were significantly more effective in reducing gray mold symptoms incited by a $\Delta$ BcatrB mutant than by the parental strain. We conclude that the $\mathrm{ABC}$ transporter BcatrB provides protection to $B$. cinerea in phenazine-mediated interactions with Pseudomonas spp. Collectively, these results indicate that fungal $\mathrm{ABC}$ transporters can play an important role in antibiotic-mediated interactions between bacteria and fungi in plant-associated environments. The implications of these findings for the implementation and sustainability of crop protection by antagonistic microorganisms are discussed.

Soil and plant-associated environments harbor a wide variety of microorganisms that play an integral role in plant growth and in preservation of multiple ecosystem functions. To exist in natural environments, microorganisms must be able to endure all of the adverse abiotic and biotic conditions that are prevalent in a particular environment. Among the biotic

Corresponding author: M. A. De Waard; Telephone +31 317 483123; Fax: +31 317 483412; E-mail: maarten.dewaard@wur.nl.

Current address of H.-J. Schoonbeek: Department of Biology, Unit of Plant Biology, Route Albert Gockel 3, 1700 Fribourg Switzerland.

* The $\boldsymbol{e}$-Xtra logo stands for "electronic extra" and indicates the HTML abstract available on-line contains supplemental material not included in the print edition. Figure 3 appears in color on-line. factors, interactions within and among microbial communities are numerous and range from synergistic and mutualistic to antagonistic and parasitic. Many microorganisms isolated from soil and plant-associated environments produce secondary metabolites that adversely affect the growth or metabolic activity of other microorganisms (Fravel 1988). The significance of these antibiotics in microbial interactions in situ, however, has long been questioned because of the perceived constraints to antibiotic production in natural environments (Williams and Vickers 1986). Because of the biotic and abiotic complexity of soil and plant-associated environments, there were several inherent difficulties in demonstrating that antibiotics are produced by microorganisms in situ. Development of sensitive detection methods, including reporter gene systems and bioanalytical techniques, now have demonstrated unequivocally that antibiotic compounds are produced in situ by both introduced and indigenous microorganisms (Raaijmakers et al. 1999; Thomashow et al. 1997). In this context, considerable attention has been given to the antibiotics pyrrolnitrin (PRN), 2,4-diacetylphloroglucinol (DAPG), and phenazines produced by plant growth-promoting fluorescent Pseudomonas spp. (Thomashow and Weller 1995). These antibiotics are produced in soil and rhizosphere environments (Thomashow et al. 1997) and play a key role in interactions between Pseudomonas strains and soilborne fungi (Cook et al. 1995; Whipps 2001).

Numerous Pseudomonas strains that produce antibiotics have been isolated from the rhizosphere of plants grown in soils from diverse geographical regions (Keel et al. 1996; McSpadden Gardener et al. 2000; Raaijmakers et al. 1997). The ability of plant-associated pseudomonads to produce antibiotics enables them to defend their habitats (Mazzola et al. 1992), whereas the existence of genotypic and physiological diversity among Pseudomonas spp. producing the same antibiotic (McSpadden Gardener et al. 2000; Picard et al. 2000; Raaijmakers and Weller 2001; Wang et al. 2001) provides a means by which populations of these microorganisms can adapt to diverse habitats. Although substantial progress has been made in the identification of genes involved in the biosynthesis and regulation of antibiotic production by Pseudomonas spp. (Bangera and Thomashow 1999; Delaney et al. 2001; Hammer et al. 1997; Mavrodi et al. 1998; Pierson et al. 1995), the responses of other microorganisms, and in particular defensive mechanisms, to these antibiotics have received little attention. Studies on the effect of therapeutic antibiotics, antimycotics, and synthetic fungicides on human- and plantpathogenic microorganisms have shown that target organisms can protect themselves by active efflux mechanisms that prevent the intracellular accumulation of these compounds to toxic concentrations (Del Sorbo et al. 2000; De Waard 1997; Sanglard et al. 1998; Van Bambeke et al. 2000). Active efflux 
mechanisms not only enable target organisms to tolerate exogenous antibiotics, but also may prevent self-intoxication in antibiotic-producing microorganisms (Andrade et al. 2000a; Mendez and Salas 2001). Among the active efflux mechanisms known, ATP-binding cassette (ABC) transporters are well studied (Dassa and Bouige 2001; Del Sorbo et al. 2000; Driessen et al. 2000; Rogers et al. 2001; Wolfger et al. 2001). $\mathrm{ABC}$ transporters are present from archae-bacteria to man and enable both influx and efflux of several compounds (Andrade et al. 2000b; Kolaczkowski et al. 1998; Lewis 2001). The natural functions of $\mathrm{ABC}$ transporters from plant-pathogenic fungi comprise secretion of toxins that act as virulence factors (host-specific toxins or mycotoxins) and protection against plant defense compounds (phytoalexins) and synthetic fungicides (De Waard 1997). Over the last few years, these phenomena have been described for Botrytis cinerea, Magnaporthe grisea, and Mycosphaerella graminicola (Schoonbeek et al. 2001; Urban et al. 1999; Zwiers and De Waard 2000).

It frequently has been postulated that $\mathrm{ABC}$ transporters also may play an important role in microbial interactions in natural environments (Andrade et al. 2000b; De Waard 1997; Del Sorbo et al. 2000). To date, however, their protective role in interactions between naturally occurring microorganisms has not been addressed. The objective of this study was to investigate whether fungal $\mathrm{ABC}$ transporters are involved in antibiotic-mediated interactions between bacteria and fungi in natural environments. More specifically, we studied interactions between $B$. cinerea and antibiotic-producing Pseudomonas spp. in vitro and in situ. B. cinerea is a fungus that infects a broad range of plant species and that resides in plant debris for its survival. During both the parasitic and saprophytic stage of its life cycle, $B$. cinerea coexists and interacts with other mi-

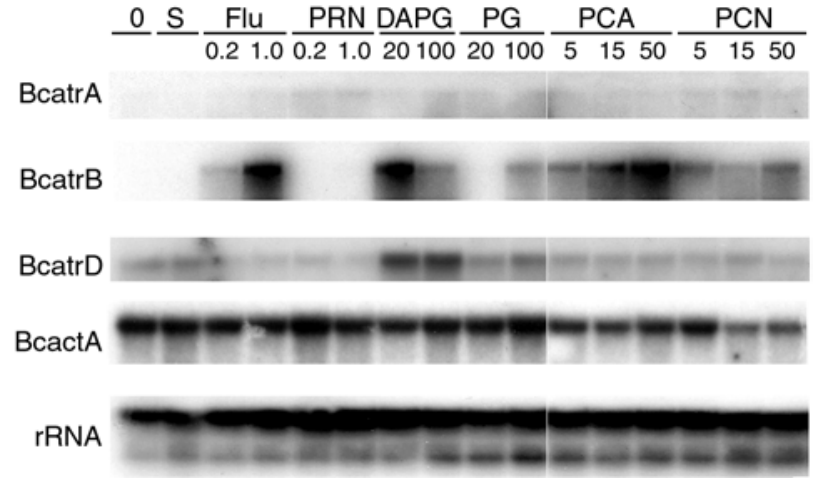

Fig. 1. Northern analysis showing the effect of fludioxonil and antibiotics on expression of BcatrA, BcatrB, and BcatrD in Botrytis cinerea strain B05.10. Germlings received a 20-min treatment: mock control (0), solvent control ( $0.1 \%$ dimethyl sulfoxide, $\mathrm{S})$, fludioxonil (Flu; 0.2 and $1 \mathrm{mg} \mathrm{l}^{-1}$ ), pyrrolnitrin (PRN; 0.2 and $1 \mathrm{mg} \mathrm{l}^{-1}$ ), 2,4-diacetylphloroglucinol (DAPG; 20 and $100 \mathrm{mg} \mathrm{l}^{-1}$ ), phloroglucinol (PG; 20 and $100 \mathrm{mg} \mathrm{l}^{-1}$ ), phenazine-1carboxylic acid (PCA; 5, 15, and $50 \mathrm{mg} \mathrm{l}^{-1}$ ), and phenazine-1-carboxamide (PCN; 5, 15, and $50 \mathrm{mg} \mathrm{l}^{-1}$ ). Loading control: ribosomal 23S RNA and BcactA. croorganisms. In B. cinerea, at least $14 \mathrm{ABC}$ transporters have been identified (Hayashi et al. 2001; Vermeulen et al. 2001), allowing the study of their role in interactions with antibioticproducing Pseudomonas spp. We observed that broad-spectrum antibiotics produced by Pseudomonas spp. induced expression of several $\mathrm{ABC}$ transporter genes in $B$. cinerea. Phenazine antibiotics strongly induced expression of the $\mathrm{ABC}$ transporter gene $B$ catr $B$, and $\triangle B$ catrB mutants were significantly more sensitive to these antibiotics than their parental strain. On tomato leaves, phenazine-producing Pseudomonas strains were significantly more effective in reducing gray mold symptoms incited by a BcatrB mutant than by its parental strain. These results show, for the first time, that specific fungal ABC transporters play an important role in microbial interactions in plant-associated environments.

\section{RESULTS}

\section{Expression of ABC transporter genes.}

The effect of the fungicide fludioxonil and the Pseudomonas antibiotics PRN, DAPG, phloroglucinol (PG), phenazine-1carboxylic acid (PCA), and phenazine-1-carboxamide (PCN) on expression of ABC transporter genes BcatrA, B, C, D, E, F, $G, I$, and $K$ in $B$. cinerea germlings was studied by northern analysis. Treatment of germlings with fludioxonil or antibiotics for $20 \mathrm{~min}$ had no effect on the expression of BcatrA (Fig. 1), BcatrC, BcatrE, BcatrF, BcatrG, BcatrI, and BcatrK (data not shown). Treatment with PRN did not induce expression of any of the $\mathrm{ABC}$ transporter genes tested, whereas fludioxonil, a fungicide derived from PRN (Ligon et al. 2000), resulted in highly elevated expression levels of BcatrB (Fig. 1). Treatment with the antibiotics DAPG, PG, PCA, and PCN had a differential effect on expression of BcatrB and BcatrD (Fig. 1). DAPG and the phenazines PCA and PCN strongly induced BcatrB expression. Treatment with PG also resulted in elevated transcript levels of BcatrB, but expression levels were lower than those obtained with DAPG and PCA. DAPG and, to a lesser extent, PG also induced expression of BcatrD. The induction patterns obtained after $60 \mathrm{~min}$ of treatment were similar to the patterns obtained after $20 \mathrm{~min}$ (data not shown). Expression of the actin gene BcactA, an indicator of fungal growth and transcription, was constant for all treatments. These results clearly demonstrate that several antibiotics produced by Pseudomonas spp. induce expression of specific ABC transporter genes in $B$. cinerea, in particular BcatrB. For this reason, further studies on antibiotic-mediated interactions between $B$. cinerea and Pseudomonas spp. focused on BcatrB.

\section{Antifungal activity of antibiotics.}

Compounds that induce expression of $\mathrm{ABC}$ transporter genes also can be substrates of the encoded proteins. In that case, replacement of the gene involved may cause an increased sensitivity to these compounds. The activity of fludioxonil, PRN, DAPG, PG, PCA, and PCN was tested on radial mycelial growth of wild-type $B$. cinerea strain B05.10 and two independent $\Delta \mathrm{Bcatr} B$ mutants; a $\Delta \mathrm{B}$ catrA mutant was included as a

Table 1. Effect of fludioxonil and antibiotics on radial mycelial growth of Botrytis cinerea strain B05.10 and its derivatives

\begin{tabular}{|c|c|c|c|c|c|}
\hline \multirow[b]{2}{*}{ Strain } & \multicolumn{5}{|c|}{$\mathrm{EC}_{50}\left(\mathrm{mg} \mathrm{liter}^{-1}\right)^{\mathrm{z}}$} \\
\hline & Fludioxonil & Pyrrolnitrin & DAPG & PCA & PCN \\
\hline B05.10 & $0.0022 \mathrm{a}$ & $0.019 \mathrm{a}$ & $17.4 \mathrm{a}$ & $39 \mathrm{a}$ & $40 \mathrm{a}$ \\
\hline$\Delta$ BcatrA-M7 & $0.0023 \mathrm{a}$ & $0.022 \mathrm{a}$ & $17.2 \mathrm{a}$ & $36 \mathrm{a}$ & $43 \mathrm{a}$ \\
\hline$\Delta \mathrm{BcatrB} 4$ & $0.0013 \mathrm{~b}$ & $0.019 \mathrm{a}$ & $16.9 \mathrm{a}$ & $13 \mathrm{~b}$ & $19 \mathrm{~b}$ \\
\hline$\triangle \mathrm{BcatrB} 5$ & $0.0013 \mathrm{~b}$ & $0.021 \mathrm{a}$ & $15.8 \mathrm{a}$ & $8.2 \mathrm{~b}$ & $12 \mathrm{~b}$ \\
\hline
\end{tabular}

${ }^{\mathrm{z}}$ Effective concentration of compounds resulting in inhibition of radial mycelial growth by $50 \%\left(\mathrm{EC}_{50}\right)$; DAPG $=2,4-$ diacetylphloroglucinol; PCA $=$ phenazine-1-carboxylic acid; $\mathrm{PCN}=$ phenazine-1-carboxamide. Different letters in the same column indicate a statistically significant difference $(P=0.05)$. 
control (Table 1). Both $\triangle \mathrm{BcatrB}$ mutants were significantly more sensitive to PCA and PCN than their parental strain B05.10. Spore germination experiments confirmed this differential sensitivity to these phenazines (data not shown). The $\triangle B$ catrB mutants also were more sensitive to fludioxonil than B05.10, as reported previously (Vermeulen et al. 2001), whereas no differences were observed in sensitivity to PRN and DAPG (Table 1). PG did not adversely affect mycelial growth of any of the $B$. cinerea strains at concentrations up to $500 \mu \mathrm{g} \mathrm{ml}^{-1}$, suggesting that acetylation of PG significantly increases its fungicidal activity (data not shown). $\triangle$ BcatrA-M7 did not differ from its parental strain in sensitivity to any of the tested compounds, indicating that BcatrA is not involved in protection against any of these compounds. Collectively, these results strongly suggest that the ABC transporter BcatrB in $B$. cinerea provides protection not only to the fungicide fludioxonil but also to the antibiotics PCA and PCN.

\section{Effect of phenazines on accumulation of $\left[{ }^{14} \mathrm{C}\right]$ fludioxonil.}

The effect of phenazines on the efflux activity of BcatrB was determined in $\left[{ }^{14} \mathrm{C}\right]$ fludioxonil accumulation experiments with germlings of wild-type strain B05.10 (Fig. 2). Accumulation of $\left[{ }^{14} \mathrm{C}\right]$ fludioxonil, a substrate of BcatrB, was transient: the maximum level of $\left[{ }^{14} \mathrm{C}\right]$ fludioxonil accumulation was

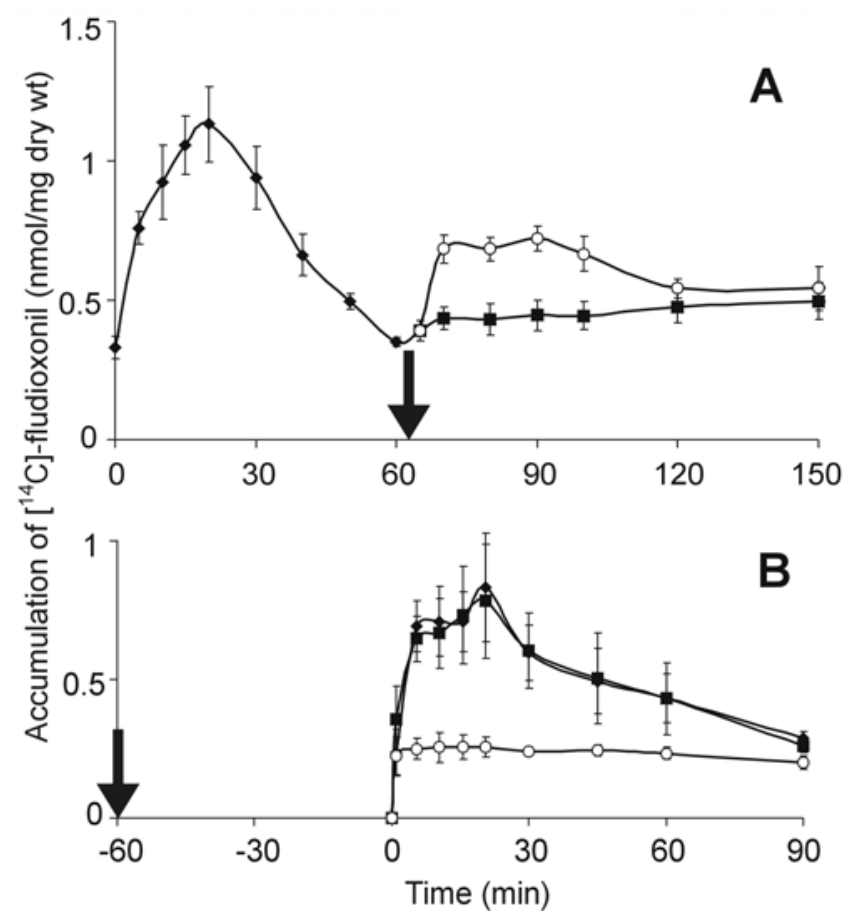

Fig. 2. Effect of phenazine-1-carboxamide (PCN) on $\left[{ }^{14} \mathrm{C}\right]$ fludioxonil accumulation by germlings of Botrytis cinerea strain B05.10. Arrows indicate the addition of PCN A, 65 min after or B, 60 min prior to addition of $\left[{ }^{14} \mathrm{C}\right]$ fludioxonil $\left(1 \mathrm{mg} \mathrm{l}^{-1}\right)$ at $t=0$. Treatments: control $=\diamond$, solvent control $(0.1 \%$ dimethyl sulfoxide $)=\mathbf{\square}$, and PCN $\left.\left(10 \mathrm{mg} \mathrm{l}^{-1}\right)=\bigcirc\right)$. reached 20 min after initiation of the experiment and thereafter gradually declined and remained low from $60 \mathrm{~min}$ onward (Fig. 2A). This transient accumulation is ascribed to rapid passive influx of $\left[{ }^{14} \mathrm{C}\right]$ fludioxonil, resulting in induction of BcatrB expression and subsequent active efflux. Addition of PCN 65 min after initiation of the experiment resulted in an instantaneous and transient increase in accumulation of $\left[{ }^{14} \mathrm{C}\right]$ fludioxonil (Fig. 2A). This transient increase can be explained by competition of PCN with fludioxonil for export by BcatrB followed by additional induction of BcatrB and other transporters. A 60min pretreatment of germlings with $\mathrm{PCN}$ prior to addition of $\left[{ }^{14} \mathrm{C}\right]$ fludioxonil resulted in a low and constant accumulation level of $\left[{ }^{14} \mathrm{C}\right]$ fludioxonil (Fig. $2 \mathrm{~B}$ ), which is ascribed to induction of expression of BcatrB by PCN.

\section{Role of BcatrB in in vitro interactions \\ between $B$. cinerea and Pseudomonas spp.}

Antagonism of the bacterial strains JM13, B37w, PCL1119, PCL1391, and Phz24 toward B. cinerea strains was determined in agar diffusion tests (Table 2). JM13 does not produce any known antibiotics and showed almost no activity against all $B$. cinerea strains tested. The antagonistic activity of $\mathrm{B} 37 \mathrm{w}$, known to produce PRN, was similar to all $B$. cinerea strains tested. Antagonistic activity of PCL1391 and Phz24, known to produce phenazines, was significantly stronger toward the mutants $\triangle \mathrm{BcatrB} 4$ and B5 than to the parental strain B05.10 and $\triangle B$ catrA-M7. In contrast, PCL1119, the phenazine-deficient mutant of PCL1391, had almost no activity toward the $\Delta B$ catrB mutants and their inhibition was similar to that of the control strains. Microscopic observation of germling growth in the inhibition zones confirmed that PCL1391 had a relatively strong effect on spore germination and germ tube elongation of $\triangle$ BcatrB5 (Fig. 3). Similar observations were made in experiments with Phz24 and $\triangle \mathrm{B}$ catrB4. To ascertain that the inhibition zones incited by PCL1391 and Phz24 can be, at least in part, ascribed to activity of phenazines, the concentration of these antibiotics in the agar plates was determined by high-performance liquid chromatography (HPLC) analysis. Inhibition zones around inoculation sites of strain PCL1391 contained, on average, PCN at $30.1 \mu \mathrm{g} \mathrm{ml}^{-1}$ and zones around Phz24 contained phenazines at $37.9 \mu \mathrm{g} \mathrm{ml}^{-1}\left(2^{\prime}-\mathrm{OH}-\mathrm{PCA}\right.$ at $32.5 \mu \mathrm{g} \mathrm{ml}^{-1}$ and PCA at $5.4 \mu \mathrm{g} \mathrm{ml}^{-1}$ ). These concentrations are approximately two times higher than the effective concentration of compounds resulting in inhibition of radial mycelial growth by $50 \%\left(\mathrm{EC}_{50}\right)$ of $\mathrm{PCN}$ for the $\triangle \mathrm{BcatrB}$ mutants and 1.5 times lower than the $\mathrm{EC}_{50}$ for the parental strain B05.10 (Table 1). In zones around the inoculation site of the other bacterial strains, including PCL1119, no phenazines were detected.

\section{Role of BcatrB in in situ interactions between $B$. cinerea and Pseudomonas spp.}

The interactions between phenazine-producing Pseudomonas strains and B. cinerea strains B05.10 and $\triangle \mathrm{BcatrB} 4$ was studied on tomato leaves. The virulence of B05.10 and $\triangle \mathrm{BcatrB} 4$ on tomato leaves was similar in the control treatment (Fig. 4). Treatment of tomato leaves with cell suspen-

Table 2. Antagonistic activity of Pseudomonas and Burkholderia spp. against Botrytis cinerea strain B05.10 and its derivatives in agar diffusion tests

\begin{tabular}{|c|c|c|c|c|c|}
\hline \multirow[b]{2}{*}{ Strains } & \multicolumn{5}{|c|}{ Inhibition zone $(\mathrm{mm})^{\mathrm{z}}$} \\
\hline & JM13 & PCL1119 & PCL1391 & Phz24 & B37w \\
\hline B05.10 & $0.45 \mathrm{a}$ & $1.25 \mathrm{a}$ & $1.46 \mathrm{a}$ & $14.17 \mathrm{a}$ & $7.68 \mathrm{a}$ \\
\hline$\Delta \mathrm{BcatrA}-\mathrm{M} 7$ & $0.32 \mathrm{a}$ & $0.43 \mathrm{~b}$ & $1.12 \mathrm{a}$ & $14.46 \mathrm{a}$ & $7.01 \mathrm{a}$ \\
\hline$\Delta B$ catrB4 & $0.37 \mathrm{a}$ & $0.74 \mathrm{ab}$ & $4.85 \mathrm{~b}$ & $19.43 \mathrm{~b}$ & $8.27 \mathrm{a}$ \\
\hline$\triangle \mathrm{BcatrB} 5$ & $0.40 \mathrm{a}$ & $0.65 \mathrm{~b}$ & $4.29 \mathrm{~b}$ & $18.43 \mathrm{~b}$ & $8.30 \mathrm{a}$ \\
\hline
\end{tabular}

${ }^{\mathrm{z}}$ Different letters in the same column indicate a statistically significant difference $(P=0.05)$. 
sions of PCL1391 significantly reduced the percentage of expanding lesions caused by $\triangle \mathrm{BcatrB} 4$, whereas no reduction was observed for parental strain B05.10 (Fig. 4A). PCL1119, the phenazine-deficient mutant of PCL1391, did not reduce the percentage of expanding lesions for both $\triangle \mathrm{BcatrB} 4$ and B05.10. Furthermore, the effect of PCL1391 on the size and growth of the lesions caused by $\triangle \mathrm{BcatrB} 4$ was significantly stronger than for B05.10 (Fig. 4B and C). In contrast, the effect of PCL1119 on lesion size and growth was similar for B05.10 and $\triangle B$ catrB4. In the repeat experiment, similar results were obtained: PCL1391 and phenazine-producer Phz24 significantly reduced the size and growth of the lesions caused by $\triangle \mathrm{B}$ catrB 4 , whereas no reduction was observed for parental strain B05.10. HPLC analysis demonstrated that, on leaves treated with PCL1391, PCN was produced at an average concentration of $5.6 \mu \mathrm{g} \mathrm{g}^{-1}$ of leaf fresh weight. No phenazines were detected on untreated leaves or on leaves treated with PCL1119. These results indicate that the ABC transporter BcatrB provides protection to $B$. cinerea in phenazine-mediated interactions with Pseudomonas spp.

\section{DISCUSSION}

In natural environments, many microorganisms coexist in close physical association, leading to numerous types of interactions. For their survival, microorganisms have developed both offensive and defensive strategies to effectively compete with other organisms. Various mechanisms that enable microorganisms to resist toxic compounds have been described in the area of medical microbiology and include enzymatic degradation or inactivation of antibiotic compounds (Davies 1994), alteration of their target sites (Spratt 1994), and active efflux (Nikaido 1994; Van Bambeke et al. 2000; Van Veen and Konings 1997). To date, however, the role of these protective mechanisms in microbial interactions in natural environments has received little attention. This study shows that the $\mathrm{ABC}$ transporter BcatrB from the plant-pathogenic fungus $B$. cinerea provides protection against phenazine antibiotics produced by Pseudomonas spp. The phenazines PCA and PCN strongly induced $B c a t r B$ expression, and $\triangle B c a t r B$ mutants were more sensitive to phenazine antibiotics than their parental strain. In addition, accumulation of fludioxonil, a known BcatrB substrate (Vermeulen et al. 2001), was strongly affected by addition of PCN. These results indicate that phenazine antibiotics are substrates of the $\mathrm{ABC}$ transporter $\mathrm{BcatrB}$ in $B$. cinerea. In both in vitro and in situ experiments, the $\triangle B$ catrB mutants of $B$. cinerea were significantly more sensitive to antagonism by the phenazine-producing $P$. chlororaphis strain PCL1391 than the parental strain B05.10. In contrast, a phenazine-deficient mutant of PCL1391 did not show this differential activity towards the wild-type B05.10 and the $\Delta$ BcatrB mutant. Collectively, these results demonstrate, for the first time, that fungal ABC transporters can play an important role in microbial interactions in plant-associated environments and, more specifically, protect a fungal pathogen against antibiotic compounds produced by antagonistic bacteria.

Interestingly, BcatrB also provides protection against the grapevine phytoalexin resveratrol and phenylpyrrole fungicides (Schoonbeek et al. 2001; Vermeulen et al. 2001), indicating that one $\mathrm{ABC}$ transporter can transport multiple and structurally diverse compounds. $\mathrm{ABC}$ transporters with a wide substrate range have also been reported for yeasts and other filamentous fungi (Andrade et al. 2000a; Kolaczkowski et al. 1998; Moore et al. 2000; Rogers et al. 2001; Wolfger et al. 2001). At present, it is not known how multiple unrelated compounds can induce transcription of one particular gene and at the same time act as a substrate of the encoded protein. Our observation that fludioxonil, a fungicide derived from pyrrolnitrin (Ligon et al. 2000), differs from pyrrolnitrin in its induction of BcatrB and in activity toward $\triangle \mathrm{Bcatr} B$ mutants, is surprising and may provide an approach to further elucidate substrate specificity of BcatrB. In addition to phenazine antibiotics, the antibiotics DAPG and PG also induced expression of BcatrB. However, both $\triangle B$ catr $B$ mutants showed sensitivity to these compounds similar to that of their parental strain, indicating that induction of expression of a particular ABC gene does not necessarily imply that the encoded protein is a major transporter of that compound. This also has been observed for other inducers of BcatrB expression, including azole fungicides (Hayashi et al. 2001; Schoonbeek et al. 2001). DAPG also induces expression of BcatrD; therefore, this transporter may have operated in $B$ catrB mutants, thereby compensating for BcatrB efflux deficiency. The role of BcatrD and other transporters, including members of the Major Facilitator Superfamily, are currently being analyzed to better understand their role in sensitivity of B. cinerea to DAPG, a key metabolite in interactions between several plant pathogens and fluorescent Pseudomonas strains (Walsh et al. 2001). The contribution of other protective mechanisms, including enzymes that reduce oxidative stress caused by antibiotics (Levy et al. 1992), will be included in these studies.

An interesting question arising from this study is how $B$. cinerea acquired resistance to phenazine antibiotics. We propose that this ability may have evolved from long-lasting selection pressure by phenazine-producing microorganisms during the saprophytic and pathogenic stages of the life cycle of $B$. cinerea. This may be a consequence of the fact that phenazine production is a widely distributed trait among different bacterial genera that are ubiquitous in soil and plantassociated environments (Turner and Messenger 1986). This hypothesis would imply that BcatrB homologues also are more prevalent among other saprophytic and pathogenic fungi. Studies on the distribution of BcatrB homologues in other fungi, including Aspergillus nidulans, Fusarium oxysporum, Gaeumannomyces graminis var. tritici, and Mycosphaerella
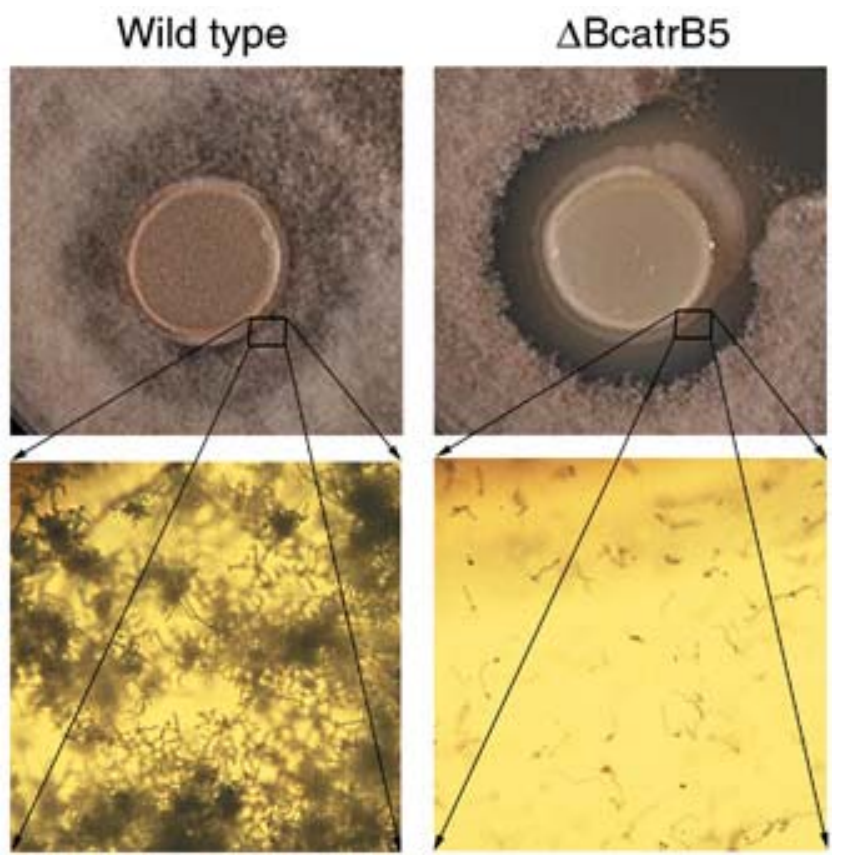

Fig. 3. Antagonistic activity of Pseudomonas chlororaphis strain PCL1391 against Botrytis cinerea B05.10 and $\Delta$ BcatrB5, in agar diffusion tests. Inhibition of mycelial growth (top) and germination of conidia ( $\times 400$ magnification, bottom). 
graminicola, are ongoing in our laboratory and will further extend our insight into the role of $\mathrm{ABC}$ transporters in antibioticmediated interactions between pathogenic fungi and antagonistic microorganisms and, more generally, in ecological equilibria between microorganisms in natural environments.

Our observation that a plant-pathogenic fungus harbors a resistance mechanism to defend itself against a natural antibiotic compound has several implications for the efficacy and implementation of antagonistic microorganisms for biocontrol purposes. It may suggest that, if sufficient selection pressure is applied to target pathogens, either by repeated inundative applications of biocontrol agents or by introducing transgenic strains with enhanced antibiotic production, shifts in pathogen populations toward resistance may occur. Information on resistance development of pathogens to antibiotics produced by biocontrol agents is very limited. One of the few, but wellstudied, examples is agrocin 84 resistance in Agrobacterium tumefaciens resulting from transfer of plasmid pAgK84 from the antagonistic strain Agrobacterium radiobacter K84 to the pathogen (Stockwell et al. 1996). Repetitive treatment of Astilbe plants with the biocontrol agent Bacillus subtilis CL27 resulted in an increase in gray mold (Li and Leifert 1994). Recently, it was shown that introduction of a phenazine-producing Pseudomonas biocontrol strain exerted transient effects on the composition of the fungal rhizosphere microflora (Glandorf et al. 2001). Furthermore, Jones and Pettit (1987) observed variation in sensitivity among anastomosis groups of Rhizoctonia solani to the antibiotic gliotoxin produced by Gliocladium virens. Mazzola and associates (1995) showed that various isolates of the take-all fungus Gaeumannomyces graminis var. tritici differ in their sensitivity toward DAPG and phenazines produced by Pseudomonas spp. In fact, the fungal isolates that were relatively insensitive to either DAPG or phenazines in vitro could no longer be suppressed in situ by Pseudomonas strains producing these antibiotics (Mazzola et al. 1995).
These results suggest that at least certain pathogen populations have the potential to develop resistance to antibiotics produced by antagonistic microorganisms. We postulate that the efficacy and sustainability of crop protection by antibiotic-producing biocontrol agents can be compromised by adaptation in target organisms and that overexpression of $\mathrm{ABC}$ transporters can act as one of the resistance mechanisms. One approach to counteract such a resistance development might be the selection of crop cultivars with traits that promote efficacy of biocontrol agents (Smith et al. 1999). This may apply to crop cultivars with enhanced production of secondary metabolites that act as modulators (e.g., flavonoids) of fungal $\mathrm{ABC}$ transporter activity (Conseil et al. 2000).

\section{MATERIALS AND METHODS}

Strains and cultural practices.

Characteristics of the bacterial and fungal strains used in this study are described in Table 3. Botrytis cinerea strains were stored as conidial suspensions in $15 \%$ glycerol at $-80^{\circ} \mathrm{C}$ and cultured as described previously (Schoonbeek et al. 2001). Conidia for sensitivity assays, expression analysis, and accumulation experiments were harvested from 10-day-old cultures on malt extract agar plates (MEA; $50 \mathrm{~g} \mathrm{l}^{-1}$ ) (Oxoid, Basingstoke, Hampshire, U.K.), amended with yeast extract $\left(2 \mathrm{~g} \mathrm{l}^{-1}\right.$; Oxoid). Bacterial isolates were stored in $40 \%$ glycerol at $-80^{\circ} \mathrm{C}$ and cultured on King's medium B (KMB) (King et al. 1954) at $28^{\circ} \mathrm{C}$ in the dark.

\section{Chemicals.}

Fludioxonil (technical grade) and $\left[{ }^{14} \mathrm{C}\right]$ fludioxonil were kindly provided by Syngenta (Basel, Switzerland). The antibiotics used were PG (1,3,5-trihydroxybenzene; Eastman Kodak Company, Rochester, NY, U.S.A.), DAPG (HPLC-purified), PRN (Syngenta), PCA, and PCN (T. F. C. Chin-A-Woeng,
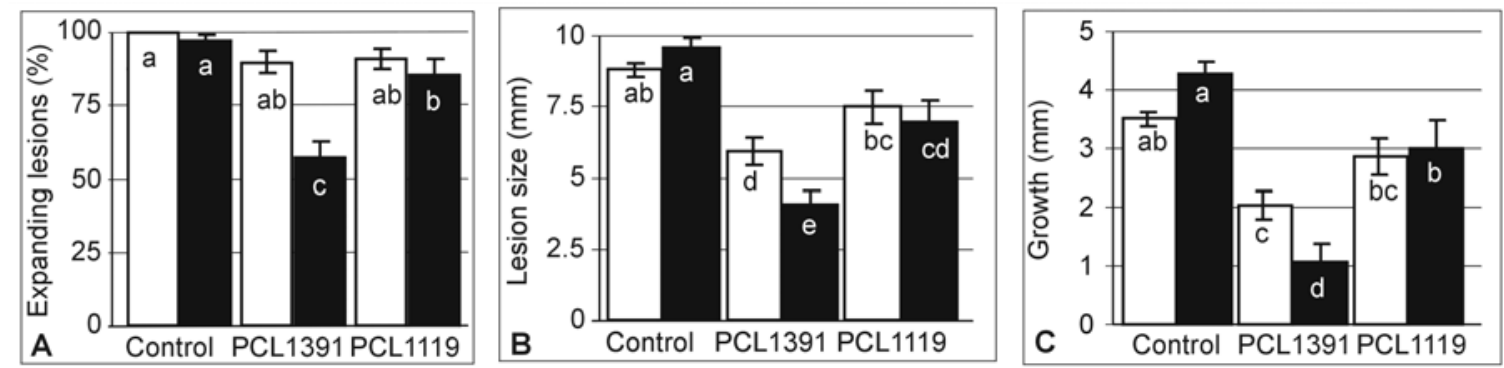

Fig. 4. Antagonistic activity of Pseudomonas chlororaphis PCL1391 and its phenazine-deficient mutant PCL1119 on disease development incited by Botrytis cinerea strains B05.10 (white) and $\triangle \mathrm{B}$ catrB4 (black) on tomato leaves. Leaves were sprayed with sodium phosphate buffer (control), or a suspension of PCL1391 or PCL1119 in the same phosphate buffer. Disease development is expressed as A, the percentage of inoculation sites developing into expanding lesions, B, the average lesion size at 4 days postinoculation (dpi), and $\mathbf{C}$, the average growth of the lesions between 3 and 4 dpi. Different letters in columns indicate statistically significant differences between treatments $(P=0.05)$.

Table 3. Characteristics of bacterial and Botrytis cinerea strains

\begin{tabular}{ll}
\hline Strain & \\
\hline Botrytis cinerea & Haploid derivative of SAS56 with wild-type sensitivity (Buttner et al. 1994) \\
B05.10 & BcatrA gene-replacement mutant derived from B05.10 (Del Sorbo, unpublished data) \\
$\Delta$ BcatrA-M7 & BcatrB gene-replacement mutants derived from B05.10 with increased sensitivity to fludioxonil (Schoonbeek et al. 2001) \\
$\Delta$ BcatrB4 and $\Delta$ BcatrB5 & Producer of PRN (Burkhead et al. 1994) \\
Burkholderia cepacia & \\
B37w (ATCC51671) & Producer of PCA and PCN (Chin-A-Woeng et al. 1998) \\
Pseudomonas chlororaphis & Mutant of PCL1391 with a Tn5-luxAB insertion in the phzB gene (Chin-A-Woeng et al. 1998) \\
PCL1391 & \\
PCL1119 & No production of known antibiotics (Raaijmakers and De Souza, unpublished data) \\
Pseudomonas sp. & Producer of PRN, PCA, 2'OH-PCA (Raaijmakers and Lemanceau, unpublished data) \\
JM13 & Phz24
\end{tabular}

${ }^{\mathrm{z}} \mathrm{PRN}=$ pyrrolnitrin, $\mathrm{PCA}=$ phenazine-1-carboxylic acid, $\mathrm{PCN}=$ phenazine-1-carboxamide . 
Leiden University, Leiden, The Netherlands). All other compounds were purchased from Sigma-Aldrich (Zwijndrecht, The Netherlands). Compounds were added to media from 1,000-fold concentrated stock solutions in dimethyl sulfoxide unless stated otherwise.

\section{In vitro sensitivity assays.}

The $\mathrm{EC}_{50}$ was determined on potato dextrose agar (PDA; Oxoid) as described previously (Stehmann and De Waard 1996). Experiments were repeated three times.

\section{Gene expression in $B$. cinerea.}

Expression analysis of $\mathrm{ABC}$ transporter genes in $B$. cinerea germlings was performed as described previously (Schoonbeek et al. 2001). Gene-specific fragments of BcatrA, BcatrB, and $B$ catrD and fragments corresponding to expressed sequence tags of BcatrC, BcatrE, BcatrF, BcatrG, BcatrI, and BcatrK were described previously (Hayashi et al. 2001; Vermeulen et al. 2001). Mycelium frozen in liquid nitrogen was used for RNA isolation with TRIzol (Life Technologies, Breda, The Netherlands). Hybridizations with $B$. cinerea 23S rRNA and $B$ cactA (actin gene) were used as control (Prins et al. 2000).

\section{Accumulation of $\left[{ }^{14} \mathrm{C}\right]$ fludioxonil.}

Accumulation experiments were performed as described previously (Vermeulen et al. 2001) with minor modifications. Standard germling suspensions, consisting of $200 \mathrm{mg}$ (wet weight $)$ of mycelium in $50 \mathrm{ml}$ of buffer $(23.4 \mathrm{mM}$ potassium phosphate [pH 6.0], $0.1 \mathrm{mM} \mathrm{CaCl}_{2}$, glucose at $10 \mathrm{~g} \mathrm{l}^{-1}$ ) in 300 $\mathrm{ml}$ Erlenmeyer flasks, were shaken on a reciprocal shaker (120 $\mathrm{rpm})$ at $20^{\circ} \mathrm{C}$. Experiments were initiated by adding $\left[{ }^{14} \mathrm{C}\right]$ fludioxonil to a final concentration of $0.4 \mu \mathrm{M}\left(1 \mathrm{mg} \mathrm{l}^{-1}\right.$;

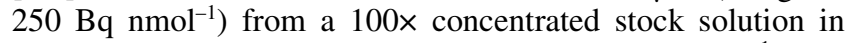
methanol. The effect of phenazines $\left(10 \mathrm{mg} \mathrm{l}^{-1}\right)$ on $\left[{ }^{14} \mathrm{C}\right]$ fludioxonil accumulation was determined by addition 60 min prior to or after the start of the incubation with the radiochemical. Experiments were performed in triplicate.

\section{In vitro interactions}

between Pseudomonas spp .and $B$. cinerea.

All bacterial isolates were transferred from a single colony on $\mathrm{KMB}$ agar to $3 \mathrm{ml}$ of $\mathrm{KMB}$ broth and incubated (180 rpm) at $28^{\circ} \mathrm{C}$ for $16 \mathrm{~h}$. Bacterial suspensions $(0.5 \mathrm{ml})$, mixed with PDA $\left(50 \mathrm{ml} ; 12 \mathrm{~g}\right.$ of PDA and agar at $\left.8 \mathrm{~g} \mathrm{l}^{-1}\right)$ at $42^{\circ} \mathrm{C}$, were added to petri dishes $(15 \mathrm{~cm})$ and incubated in the dark at $25^{\circ} \mathrm{C}$ for 10 days. Petri dishes $(15-\mathrm{cm})$ containing half-strength MEA (50 ml; $25 \mathrm{~g}$ of MEA and agar at $\left.6 \mathrm{~g} \mathrm{l}^{-1}\right)$ mixed with fungal spores $\left(5 \times 10^{4}\right.$ spores $\left.\mathrm{ml}^{-1}\right)$ at $42^{\circ} \mathrm{C}$ were prepared on a horizontal surface. After solidification, agar plugs (diameter, $18 \mathrm{~mm}$ ) from plates with bacteria were placed on the plates containing fungal spores. After incubation at $19^{\circ} \mathrm{C}$ in the dark for 3 days, the radius of the inhibition zone surrounding the bacterial plugs was measured. Tests were performed in quadruplicate and repeated three times.

\section{In situ interactions \\ between Pseudomonas spp. and $B$. cinerea.}

The effect of phenazine-producing Pseudomonas strains on infection of tomato leaves by $B$. cinerea was tested using a standardized assay that allows comparison of two $B$. cinerea strains per leaf (Benito et al. 1998). Bacteria were spread on $\mathrm{KMB}$ agar, incubated at $25^{\circ} \mathrm{C}$ for 2 days, washed, and resuspended in sodium phosphate buffer $(10 \mathrm{mM}, \mathrm{pH} 6.4)$ to an optical density at $600 \mathrm{~nm}$ of 1.0. Leaves were cut from 5- to 7week-old tomato plants (cv. Moneymaker- $C f 4$ ), placed in wet florist foam, and incubated in plastic boxes. Leaves (four per treatment) were sprayed with suspensions of phenazine-pro- ducing strains PCL1391 or its phenazine-deficient mutant PCL1119 until run-off, using a DeVilbiss sprayer. The phenazine-producing strain Phz24 was included in a replicate experiment. Control leaves were sprayed with buffer. Leaves were incubated in boxes with closed lids for $26 \mathrm{~h}$ at $15^{\circ} \mathrm{C}$, opened, and dried prior to inoculation with $B$. cinerea. For each treatment, 24 leaflets were inoculated on the upper side with droplets $(2 \mu \mathrm{l})$ of a conidial suspension $\left(10^{6} \mathrm{ml}^{-1}\right)$ in Gamborg's B5 medium (Duchefa, Haarlem, The Netherlands) supplemented with $1 \%$ glucose and $10 \mathrm{mM}$ ammonium phosphate ( $\mathrm{pH}$ 6.5). The left half of each leaflet was inoculated with five droplets of B05.10 and the right half with five droplets of $\triangle \mathrm{BcatrB} 4$. Boxes were closed and incubated at $15^{\circ} \mathrm{C}$ in the dark and the diameter and growth of the lesions were determined after 3 and 4 days.

\section{Quantification of phenazine antibiotics by HPLC.}

In vitro and in situ phenazine production levels were determined by HPLC $\left(\mathrm{C}_{18}\right.$ reverse phase $5 \mu \mathrm{m}, 3.9$-by- $150 \mathrm{~mm}$ column, 616 pump, 600S controller, 996 photodiode array detector; Waters, Milford, MA, U.S.A.) (Bonsall et al. 1997). Production levels in the in vitro assays were determined by extraction of the inhibition zone surrounding the bacterial plugs. In situ production levels of PCN were determined 5 days after application of bacterial strains to tomato leaves. Approximately $5 \mathrm{~g}$ of leaf fresh weight was extracted with $80 \%$ acetone, filtered, extracted twice with ethylacetate plus $0.1 \%$ trifluoroacetic acid (TFA), air dried, and resuspended in $35 \%$ acetonitrile plus $0.1 \%$ TFA (Bonsall et al. 1997). For each treatment, two replicates were used. For quantification of phenazine production, a five-point standard curve generated by spiking known concentrations of PCN was used. A highly significant linear relationship was found for the standard curve $(\mathrm{PCN}=0.000125 \times \mathrm{A}$ $\left(r^{2}=0.99, P<0.0001\right)$, in which PCN represents the total amount of PCN (ng), and A represents the area of the PCN peak at $248 \mathrm{~nm}$.

\section{Statistical analysis.}

Differences between treatments were determined by analysis of variance followed by Duncan's multiple range test $(\alpha=$ 0.05) (SAS Institute Inc., Cary, NC, U.S.A.).

\section{ACKNOWLEDGMENTS}

This project was supported by the Council for Earth and Life Sciences (ALW), which is subsidized by The Netherlands Organization for Scientific Research (project 805-22-462). The contribution of J. M. Raaijmakers has been made possible by a fellowship from the Royal Netherlands Academy of Arts and Sciences. We thank B. J. J. Lugtenberg, G. V. Bloemberg, and T. F. C. Chin-A-Woeng (Leiden University, The Netherlands) for providing P. chlororaphis PCL1391 and PCL1119 and purified PCA and PCN; J. G. M Van Nistelrooy for technical assistance in the accumulation experiments; P. J. G. M. De Wit for critically reading the manuscript; and A. Andrade and L.-H. Zwiers for stimulating discussions.

\section{LITERATURE CITED}

Andrade, A. C., Del Sorbo, G., Van Nistelrooy, J. G. M., and De Waard, M. A. 2000a. The ABC transporter AtrB from Aspergillus nidulans mediates resistance to all major classes of fungicides and some natural toxic compounds. Microbiology 146:1987-1997.

Andrade, A. C., Van Nistelrooy, J. G. M., Peery, R. B., Skatrud, P. L., and De Waard, M. A. 2000b. The role of ABC transporters from Aspergillus nidulans in protection against cytotoxic agents and in antibiotic production. Mol. Gen. Genet. 263:966-977.

Bangera, M. G., and Thomashow, L. S. 1999. Identification and characterization of a gene cluster for synthesis of the polyketide antibiotic 2,4diacetylphloroglucinol from Pseudomonas fluorescens Q2-87. J. Bacteriol. 181:3155-63.

Benito, E. P., Ten Have, A., Van't Klooster, J. W., and Van Kan, J. A. L. 1998. Fungal and plant gene expression during synchronized infection 
of tomato leaves by Botrytis cinerea. Eur. J. Plant Pathol. 104:207-220.

Bonsall, R. F., Weller, D. M., and Thomashow, L. S. 1997. Quantification of 2,4-diacetylphloroglucinol produced by fluorescent Pseudomonas spp. in vitro and in the rhizosphere of wheat. Appl. Environ. Microbiol. 63:951-955.

Burkhead, K. D., Schisler, D. A., and Slininger, P. J. 1994. Pyrrolnitrin production by biological control agent Pseudomonas cepacia $\mathrm{B} 37 \mathrm{w}$ in culture and in colonized wounds of potatoes. Appl. Environ. Microbiol. 60:2031-2039.

Buttner, P., Koch, F., Voigt, K., Quidde, T., Risch, S., Blaich, R., Bruckner, B., and Tudzynski, P. 1994. Variations in ploidy among isolates of Botrytis cinerea: Implications for genetic and molecular analyses. Curr. Genet. 25:445-50.

Chin-A-Woeng, T. F. C., Bloemberg, G. V., Van Der Bij, A. J., Van Der Drift, K. M. G. M., Schripsema, J., Kroon, B., Scheffer, R. J., Keel, C., Bakker, P. A. H. M., Tichy, H.-V., De Bruijn, F. J., Thomas-Oates, J. E., and Lugtenberg, B. J. J. 1998. Biocontrol by phenazine-1-carboxamideproducing Pseudomonas chlororaphis PCL1391 of tomato root rot caused by Fusarium oxysporum f. sp. radicis-lycopersici. Mol. PlantMicrobe Interact. 11:1069-1077.

Conseil, G., Decottignies, A., Jault, J.-M., Comte, G., Barron, D., Goffeau, A., and Di Pietro, A. 2000. Prenyl-flavonoids as potent inhibitors of the Pdr5p multidrug ABC transporter from Saccharomyces cerevisiae. Biochemistry 39:6910-6917.

Cook, R. J., Thomashow, L. S., Weller, D. M., Fujimoto, D., Mazzola, M., Bangera, G., and Kim, D. S. 1995. Molecular mechanisms of defense by rhizobacteria against root disease. Proc. Natl. Acad. Sci. U.S.A. 92:4197-4201.

Dassa, E., and Bouige, P. 2001. The ABC of ABCs: A phylogenetic and functional classification of $\mathrm{ABC}$ systems in living organisms. Res. Microbiol. 152:211-229.

Davies, J. 1994. Inactivation of Antibiotics and the Dissemination of Resistance Genes. Science 264:375-382.

Delaney, S. M., Mavrodi, D. V., Bonsall, R. F., and Thomashow, L. S 2001. phzO, a gene for biosynthesis of 2-hydrolyated phenazine compounds in Pseudomonas aureofaciens 30-84. J. Bacteriol. 183:318-327.

Del Sorbo, G., Schoonbeek, H., and De Waard, M. A. 2000. Fungal transporters involved in efflux of natural toxic compounds and fungicides. Fungal Genet. Biol. 30:1-15.

De Waard, M. A. 1997. Significance of ABC transporters in fungicide sensitivity and resistance. Pestic. Sci. 51:271-275.

Driessen, A. J., Rosen, B. P., and Konings, W. N. 2000. Diversity of transport mechanisms: Common structural principles. Trends Biochem. Sci. 25:397-401.

Fravel, D. R. 1988. Role of antibiosis in the biocontrol of plant diseases. Annu. Rev. Phytopathol. 26:75-91.

Glandorf, D. C. M., Verheggen, P., Jansen, T., Jorritsma, J.-W., Smit, E., Leeflang, P., Wernars, K., Thomashow, L. S., Laureijs, E., ThomasOates, J. E., Bakker, P. A. H. M., and van Loon, L. C. 2001. Effect of genetically modified Pseudomonas putida WCS358r on the fungal rhizosphere microflora of field-grown wheat. Appl. Environ. Microbiol. 67:3371-3378.

Hammer, P. E., Hill, D. S., Lam, S. T., Van Pee, K. H., and Ligon, J. M. 1997. Four genes from Pseudomonas fluorescens that encode the biosynthesis of pyrrolnitrin. Appl. Environ. Microbiol. 63:2147-2154.

Hayashi, K., Schoonbeek, H., Sugiura, H., and De Waard, M. 2001. Multidrug resistance in Botrytis cinerea associated with Decreased accumulation of the azole fungicide oxpoconazole and increased transcription of the ABC transporter gene BcatrD. Pestic. Biochem. Physiol. 70:168179

Jones, R. W., and Pettit, R. E. 1987. Variation in sensitivity among anastomosis groups of Rhizoctonia solani to the antibiotic gliotoxin. Plant Dis. 71:34-36

Keel, C., Weller, D. M., Natsch, A., Defago, G., Cook, R. J., and Thomashow, L. S. 1996. Conservation of the 2,4-diacetylphloroglucinol biosynthesis locus among fluorescent Pseudomonas strains from diverse geographic locations. Appl. Environ. Microbiol. 62:552-63.

King, E. O., Ward, M. K., and Raney, D. E. 1954. Two simple media for the demonstration of pyocyanin and fluorescein. J. Lab. Clin. Med. 44:301-307

Kolaczkowski, M., Kolaczowska, A., Luczynski, J., Witek, S., and Goffeau, A. 1998. In vivo characterization of the drug resistance profile of the major $\mathrm{ABC}$ transporters and other components of the yeast pleiotropic drug resistance network. Microb. Drug Resist. 4:143-58.

Levy, E., Eyal, Z., Chet, I., and Hochman, A. 1992. Resistance Mechanisms of Septoria tritici to Antifungal Products of Pseudomonas. Physiol. Mol. Plant Pathol. 40:163-171.

Lewis, K. 2001. In search of natural substrates and inhibitors of MDR pumps. J. Mol. Microbiol. Biotechnol. 3:247-54.

Li, H., and Leifert, C. 1994. Development of resistance in Botryotinia fuckeliana (De-Bary) Whetzel Against the biological-control agent $\mathrm{Ba}$ cillus subtilis $\mathrm{Cl27}$. Z. Pflanzenkrankh. Pflanzenschutz J. Plant Dis. Prot. 101:414-418.

Ligon, J. M., Hill, D. S., Hammer, P. E., Torkewitz, N. R., Hofmann, D., Kempf, H. J., and Van Pee, K. H. 2000. Natural products with antifungal activity from Pseudomonas biocontrol bacteria. Pest Manage. Sci. 56:688-695.

Mavrodi, D. V., Ksenzenko, V. N., Bonsall, R. F., Cook, R. J., Boronin, A M., and Thomashow, L. S. 1998. A seven-gene locus for synthesis is of phenazine-1-carboxylic acid by Pseudomonas fluorescens 2-79. J. Bacteriol. 180:2541-2548.

Mazzola, M., Cook, R. J., Thomashow, L. S., Weller, D. M., and Pierson, L. S., III. 1992. Contribution of phenazine antibiotic biosynthesis to the ecological competence of fluorescent pseudomonads in soil habitats. Appl. Environ. Microbiol. 58:2616-2624.

Mazzola, M., Fujimoto, D. K., Thomashow, L. S., and Cook, R. J. 1995. Variation in sensitivity of Gaeumannomyces graminis to antibiotics produced by fluorescent Pseudomonas spp. and effect on biological control of take-all of wheat. Appl. Environ. Microbiol. 61:2554-2559.

McSpadden Gardener, B. B., Schroeder, K. L., Kalloger, S. E., Raaijmakers, J. M., Thomashow, L. S., and Weller, D. M. 2000. Genotypic and phenotypic diversity of phlD-containing Pseudomonas strains isolated from the rhizosphere of wheat. Appl. Environ. Microbiol. 66:1939-46.

Mendez, C., and Salas, J. A. 2001. The role of ABC transporters in antibiotic-producing organisms: Drug secretion and resistance mechanisms. Res. Microbiol. 152:341-50.

Moore, C. B., Sayers, N., Mosquera, J., Slaven, J., and Denning, D. W 2000. Antifungal drug resistance in Aspergillus. J. Infect. 41:203-220.

Nikaido, H. 1994. Prevention of drug access to bacterial targets-permeability barriers and active efflux. Science 264:382-388.

Picard, C., Di Cello, F., Ventura, M., Fani, R., and Guckert, A. 2000. Frequency and biodiversity of 2,4-diacetylphloroglucinol-producing bacteria isolated from the maize rhizosphere at different stages of plant growth. Appl. Environ. Microbiol. 66:948-955.

Pierson, L. S., Gaffney, T., Lam, S., and Gong, F. C. 1995. Molecular analysis of genes encoding phenazine biosynthesis in the biologicalcontrol bacterium Pseudomonas aureofaciens-30-84. FEMS (Fed. Eur. Microbiol. Soc.) Microbiol. 134:299-307.

Prins, T. W., Wagemakers, L., Schouten, A., and Van Kan, J. A. L. 2000 Cloning and characterization of a glutathione S-transferase homologue from the plant pathogenic fungus Botrytis cinerea. Mol. Plant Pathol. $1: 169-178$.

Raaijmakers, J. M., Bonsall, R. E., and Weller, D. M. 1999. Effect of population density of Pseudomonas fluorescens on production of 2,4 diacetylphloroglucinol in the rhizosphere of wheat. Phytopathology 89:470-475.

Raaijmakers, J. M., and Weller, D. M. 2001. Exploiting genotypic diversity of 2,4-diacetylphloroglucinol-producing Pseudomonas spp.: Characterization of superior root-colonizing P. fluorescens strain Q8r1-96. Appl. Environ. Microbiol. 67:2545-54.

Raaijmakers, J. M., Weller, D. M., and Thomashow, L. S. 1997. Frequency of antibiotic-producing Pseudomonas spp. in natural environments. Appl. Environ. Microbiol. 63:881-887.

Rogers, B., Decottignies, A., Kolaczkowski, M., Carvajal, E., Balzi, E. and Goffeau, A. 2001. The pleitropic drug ABC transporters from Saccharomyces cerevisiae. J. Mol. Microbiol. Biotechnol. 3:207-14.

Sanglard, D., Ischer, F., Calabrese, D., De Micheli, M., and Bille, J. 1998. Multiple resistance mechanisms to azole antifungals in yeast clinical isolates. Drug Resist. Update 1:255-265.

Schoonbeek, H., Del Sorbo, G., and De Waard, M. A. 2001. The ABC transporter BcatrB affects the sensitivity of Botrytis cinerea to the phytoalexin resveratrol and the fungicide fenpiclonil. Mol. Plant-Microbe Interact. 14:562-571

Smith, K. P., Handelsman, J., and Goodman, R. M. 1999. Genetic basis in plants for interactions with disease-suppressive bacteria. Proc. Natl Acad. Sci. U.S.A. 96:4786-4790.

Spratt, B. G. 1994. Resistance to antibiotics mediated by target alterations Science 264:388-393

Stehmann, C., and De Waard, M. A. 1996. Sensitivity of populations of Botrytis cinerea to triazoles, benomyl and vinclozolin. Eur. J. Plant Pathol. 102:171-180.

Stockwell, V. O., Kawalek, M. D., Moore, L. W., and Loper, J. E. 1996. Transfer of pAgK84 from the biocontrol agent Agrobacterium radio bacter K84 to A. tumefaciens under field conditions. Phytopathology 86:31-37.

Thomashow, L. S., Bonsall, R. F., and Weller, D. M. 1997. Antibiotic production by soil and rhizosphere microbes in situ. Pages 493-499 in: Manual of Environmental Microbiology. C. J. Hurst, G. R. Knudsen, M. J. McInerney, L. D. Stetzenbach, and M. V. Walter, eds. ASM Press, Washington, D.C. 
Thomashow, L. S., and Weller, D. M. 1995. Current concepts in the use of introduced bacteria for biological disease control: Mechanisms and antifungal metabolites. Pages 187-235 in: Plant-Microbe Interactions, Vol. 1. G. Stacy and N. T. Keen, eds. Chapman and Hall, New York.

Turner, J. M., and Messenger, A. J. 1986. Occurrence, biochemistry and physiology of phenazine pigment production. Adv. Microb. Physiol. 27:211-75.

Urban, M., Bhargava, T., and Hamer, J. E. 1999. An ATP-driven efflux pump is a novel pathogenicity factor in rice blast disease. (Eur. Mol. Biol. Organ.) J. 18:512-521.

Van Bambeke, F., Balzi, E., and Tulkens, P. M. 2000. Antibiotic efflux pumps - commentary. Biochem. Pharmacol. 60:457-470.

Van Veen, H. W., and Konings, W. N. 1997. Drug efflux proteins in multidrug resistant bacteria. Biol. Chem. 378:769-777.

Vermeulen, T., Schoonbeek, H., and De Waard, M. A. 2001. The ABC transporter BcatrB from Botrytis cinerea is a determinant of the activity of the phenylpyrrole fungicide fludioxonil. Pest Manage. Sci. 57:393-402.
Walsh, U. F., Morrissey, J. P., and O'Gara, F. 2001. Pseudomonas for biocontrol of phytopathogens: From functional genomics to commercial exploitation. Curr. Opin. Biotechnol. 12:289-295.

Wang, C. X., Ramette, A., Punjasamarnwong, P., Zala, M., Natsch, A. Moenne-Loccoz, Y., and Defago, G. 2001. Cosmopolitan distribution of phlD-containing dicotyledonous crop-associated biocontrol pseudomonads of worldwide origin. FEMS (Fed. Eur. Microbiol. Soc.) Microbiol. Ecol. 37:105-116.

Whipps, J. M. 2001. Microbial interactions and biocontrol in the rhizosphere. J. Exp. Bot. 52:487-511.

Williams, S. T., and Vickers, J. C. 1986. Microb. Ecol. 21:43-52.

Wolfger, H., Mamnun, Y. M., and Kuchler, K. 2001. Fungal ABC proteins: Pleiotropic drug resistance, stress response and cellular detoxification Res. Microbiol. 152:375-89.

Zwiers, L.-H., and De Waard, M. A. 2000. Characterization of the ABC transporter genes $M g A t r 1$ and $M g A t r 2$ from the wheat pathogen $M y$ cosphaerella graminicola. Fungal Genet. Biol. 30:115-125. 